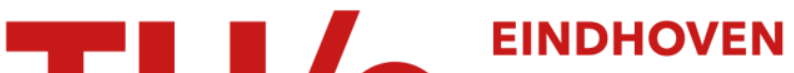 \\ UNIVERSITY OF \\ TECHNOLOGY
}

\section{Should I stay or should I go? Automated vehicles in the age of climate change}

\section{Citation for published version (APA):}

Sadeghian Borojeni, S., Meschtscherjakov, A., Pfleging, B., Donmez, B., Riener, A., Janssen, C. P., Kun, A. L., Ju, W., Remy, C., \& Wintersberger, P. (2020). Should I stay or should I go? Automated vehicles in the age of climate change. In Extended Abstracts of the $2020 \mathrm{CHI}$ Conference on Human Factors in Computing Systems [W19] Association for Computing Machinery, Inc. https://doi.org/10.1145/3334480.3375162

DOI:

10.1145/3334480.3375162

Document status and date:

Published: 25/04/2020

\section{Document Version:}

Accepted manuscript including changes made at the peer-review stage

\section{Please check the document version of this publication:}

- A submitted manuscript is the version of the article upon submission and before peer-review. There can be important differences between the submitted version and the official published version of record. People interested in the research are advised to contact the author for the final version of the publication, or visit the $\mathrm{DOI}$ to the publisher's website.

- The final author version and the galley proof are versions of the publication after peer review.

- The final published version features the final layout of the paper including the volume, issue and page numbers.

Link to publication

\section{General rights}

Copyright and moral rights for the publications made accessible in the public portal are retained by the authors and/or other copyright owners and it is a condition of accessing publications that users recognise and abide by the legal requirements associated with these rights.

- Users may download and print one copy of any publication from the public portal for the purpose of private study or research.

- You may not further distribute the material or use it for any profit-making activity or commercial gain

- You may freely distribute the URL identifying the publication in the public portal.

If the publication is distributed under the terms of Article 25fa of the Dutch Copyright Act, indicated by the "Taverne" license above, please follow below link for the End User Agreement:

www.tue.nl/taverne

Take down policy

If you believe that this document breaches copyright please contact us at:

openaccess@tue.nl

providing details and we will investigate your claim. 


\section{Should I Stay or Should I Go? Automated Vehicles in the Age of Climate Change}

\begin{tabular}{|c|c|}
\hline $\begin{array}{l}\text { Shadan Sadeghian Borojeni } \\
\text { University of Siegen } \\
\text { shadan.sadeghian@winfo.uni- } \\
\text { siegen.de }\end{array}$ & $\begin{array}{l}\text { Christian P. Janssen } \\
\text { Utrecht University } \\
\text { c.p.janssen@uu.nl }\end{array}$ \\
\hline $\begin{array}{l}\text { Alexander Meschtscherjakov } \\
\text { University of Salzburg } \\
\text { alexander.meschtscherjakov@ } \\
\text { sbg.ac.at }\end{array}$ & $\begin{array}{l}\text { Andrew L. Kun } \\
\text { University of New Hampshire } \\
\text { Andrew.Kun@unh.edu }\end{array}$ \\
\hline $\begin{array}{l}\text { Bastian Pfleging } \\
\text { Eindhoven University of } \\
\text { Technology } \\
\text { b.pfleging@tue.nl }\end{array}$ & $\begin{array}{l}\text { Wendy Ju } \\
\text { Cornell Tech } \\
\text { wendyju@cornell.edu }\end{array}$ \\
\hline $\begin{array}{l}\text { Birsen Donmez } \\
\text { University of Toronto } \\
\text { donmez@mie.utoronto.ca }\end{array}$ & $\begin{array}{l}\text { Christian Remy } \\
\text { Aarhus University } \\
\text { remy@cc.au.dk }\end{array}$ \\
\hline $\begin{array}{l}\text { Andreas Riener } \\
\text { Technische Hochschule } \\
\text { Ingolstadt (THI) } \\
\text { andreas.riener@thi.de }\end{array}$ & $\begin{array}{l}\text { Philipp Wintersberger } \\
\text { Technische Hochschule } \\
\text { Ingolstadt (THI) } \\
\text { wintersberger@carissma.eu }\end{array}$ \\
\hline
\end{tabular}

Permission to make digital or hard copies of part or all of this work for personal or classroom use is granted without fee provided that copies are not made or distributed for profit or commercial advantage and that copies bear this notice and the full citation on the first page. Copyrights for third-party components of this work must be honored. For all other uses, contact the Owner/Author.

CHI'20 Extended Abstracts, April 25-30, 2020, Honolulu, HI, USA.

(c) 2020 Copyright is held by the owner/author(s).

ACM ISBN 978-1-4503-6819-3/20/04.

https://doi.org/10.1145/3334480.3375162

\begin{abstract}
Will automated driving help or hurt our efforts to remedy climate change? The overall impact of transportation and mobility on the global ecosystem is clear: changes to that system can greatly affect climate outcomes. The design of mobility and automotive systems will influence key factors such as driving style, fuel choice, ride sharing, traffic patterns, and total mileage. However, to date, there are few research efforts that explicitly focus on these overlapping themes (automated driving \& climate changes) within the $\mathrm{HCl}$ and AutomotiveUl communities. Our intention is to grow this community and awareness of the related problems. Specifically, in this workshop, we invite designers, researchers, and practitioners from the sustainable $\mathrm{HCl}$, persuasive design, AutomotiveUI, and mobility communities to collaborate in finding ways to make future mobility more sustainable. Using embodied design improvisation and design fiction methods, we will explore the ways that systems affect behavior which then affect the environment.
\end{abstract}

\section{Author Keywords}

Automated driving; $\mathrm{CO} 2$ reduction; climate change; energy efficient driving; collective optimization; future mobility

\section{CCS Concepts}

-Human-centered computing $\rightarrow$ Human computer interaction ( $\mathrm{HCl}$ ); Ubiquitous and mobile computing; 


\section{Background}

Driving automation is a disruptive technology promising to increase drivers' safety and comfort, improve traffic throughput by providing new forms of transportation (such as shared rides or last-mile), and ultimately reduce air pollution [7]. However, achieving these goals demands much more than sophisticated technology - it requires deep transformations in society, legislation, and individual behavior. For example, driving automation might reduce the number of vehicles on the road due to shared mobility, but it could also raise traffic volume when individuals let their private vehicles circulate in cities to avoid parking costs ("ghost cars"). Being able to perform additional activities while driving could, on the positive side, improve our work-life balance, but simultaneously increase the time that we are willing to spend on the road. Thus, driving automation can lead to potentially negative outcomes that result in an increase of Green House Gases emissions [12], which lead to adverse climate change impacts with irreversible long term consequences.

In recent years, several automotive companies have adapted proactive climate strategies and focused on, and invested in, more energy-efficient products. Examples of such products are alternative powertrains (e.g., electric vehicles) and vehicles that are able to drive in platoons. These technological advances can reduce the environmental impact of human consumption. Their long-term benefit however, depends on behavioral changes that lead to curtailing consumption [6]. According to Cardner and Sternl, behaviors such as car-sharing, cutting driving speed, and lowering the thermostat on central and water heating can reduce household carbon emissions by $30 \%$ [3]. One way towards these behavioral changes or changing these "habits" is Automaticity which is overriding learned automatic cue responses by preparing an individual for an appropriate action at a specific time and place [6]. This can be facilitated through implementation of human-machine-interfaces that make alternative actions in relevant context more salient, or by providing feedback on driving behavior[6, 2].

Following the Society of Automotive Engineers' definition, driving automation comes in a gradual process in 6 levels: from level 0 in which the human has the full control of the driving manoeuvres, to level 5 where the vehicle is fully automated and can drive autonomously [21]. Until we reach level 5, we are confronted with (semi-)automated vehicles in which humans' actions and decisions influence vehicle performance in terms of eco-driving and fuel consumption. It is therefore important that the designs of the automotive user interfaces lead these decisions and actions towards more sustainable driving behavior.

Surprisingly, despite the growing need for the $\mathrm{CHI}$ and $\mathrm{Au}$ tomotiveUl communities at large to consider the impact of climate change, very little work is presented at this intersection at both flagship SIGCHI conferences $(\mathrm{CHI}$ and AutomotiveUI). One aim of the current workshop is therefore to place the importance of this topic centrally on the $\mathrm{CHI}$ and AutomotiveUl agendas, and to bring back together a group of researchers and practitioners to grow this important area. The title "Should I stay or should I go" should therefore be interpreted both literally, and figuratively. Literally, there is a consideration of whether to use the car or another form of mobility and if so, in what way to use the car to balance the various needs of transportation and mobility with sustainability. Figuratively, the title reflects the need for the overlapping $\mathrm{CHI}$ and AutomotiveUI communities to consider radical change: should we continue with our research as we do now, or should we change it more dramatically and place sustainability at the forefront?

The workshop builds on our broad experience with organizing several workshops at $\mathrm{CHI}$ and AutomotiveUI confer- 
ences addressing various questions regarding automotive user interfaces, recently looking at the transition to automated driving. We started our $\mathrm{CHI}$ workshop series with an exploration of the design space of automated vehicles from a experience-based perspective [9, 10], continued increasing our knowledge by learning from other domains such as aviation and robotics [8], and looked into concrete future scenarios of driving automation and its impact on $\mathrm{HCl}$ research and practice by gathering designers, practitioners, and researchers to gain a broader perspective [19]. Taking our knowledge from these workshops, in this workshop, we aim to look deeper in designing automotive user interfaces in the time of climate change. By using World-Café discussion method, and design practices like design fiction [20], we will explore interaction concepts for sustainable (automated) vehicles. This is not only limited to one-to-one interactions between drivers and vehicles, but also covers a wider range of users interacting with public transport systems as well as users who share their transportation spaces.

\section{Workshop Goals}

- Provide an interdisciplinary forum for designers, practitioners, and researchers in $\mathrm{HCl}$ to discuss Automotive Uls \& mobility in the age of climate change

- Discuss state-of-the-art research on (automated) driving, sustainable $\mathrm{HCl}$ [1], and how this can influence everyday life and interactions in vehicles in future scenarios

- Discuss best practices for designing Uls that assist eco-driving, and encourage environment-friendly behavioral changes, e. g., using gamification or incentives $[14,16]$

- Explore new interaction paradigms that support ecodriving behavior in (automated) vehicles

- Formulate a research manifest or research agenda to further develop initiatives in research and practice to exchange ideas and radicalize innovation at the intersection of automated driving, mobility, climate change, and sustainable $\mathrm{HCl}$

\section{Organizers}

This workshop will be organized by a team of researchers and practitioners with different disciplinary training in (sustainable) $\mathrm{HCl}$, user experience (UX), psychology, engineering, safety science, and automated driving. Many of them have been involved in organizing several workshops on topics addressing interaction with (automated) vehicles at ACM AutomotiveUI and $\mathrm{CHI}[8,9,10,19]$

Shadan Sadeghian Borojeni will be the main contact person. She is a postdoctoral researcher at the University of Siegen in Germany. Her research focuses on designing multimodal interfaces in highly automated vehicles ([18]).

Alexander Meschtscherjakov is an associate professor at the Center for $\mathrm{HCl}$ of Salzburg University. His research focus on new forms of automotive user interface design, user experience with autonomous vehicles, and persuasion to foster sustainable driving behaviour [11].

Bastian Pfleging is an assistant professor for Future Mobility at Eindhoven University of Technology, Netherlands and researcher at LMU Munich, Germany. His research interests are user interfaces for future mobility, with a focus on supporting non-driving-related activities and automated driving [13]. He actively supports the AutomotiveUI community (e.g., program chair and steering committee member).

Christian P. Janssen is an assistant professor at Utrecht University, within the division of Experimental Psychology and Helmholtz Institute. Some of his major research inter- 
ests are in multitasking and (driver) distraction, including in automated driving settings [4] .

Andrew L. Kun is professor of Electrical and Computer Engineering at the University of New Hampshire. His research focus is $\mathrm{HCl}$ in vehicles [5], including speech interaction, and the use of visual behavior and pupil diameter measures to assess and improve UI design.

Andreas Riener is a professor for $\mathrm{HMI}$ and $\mathrm{VR}$ at $\mathrm{THI}$ with co-appointment at the driving safety research center CARISSMA. At THI, he is heading an interdisciplinary research team (hcig.thi.de). His research focus is on user experience of automated driving and human factors in drivervehicle interaction. He has already worked on concepts to improve fuel economy/efficiency of road transport, e. g., with gamification, ranking list or incentives $[14,15,16]$.

Wendy $\mathrm{Ju}$ is an assistant professor of Information Science at Cornell Tech in New York City. Her research focuses on interaction with automation, particularly human-robot interactions and automated vehicle interfaces, and novel research methods to understand interaction with autonomy (e.g. [17])

Philipp Wintersberger is a researcher at the research center CARISSMA/THI and obtained his diploma in Computer Science from Johannes Kepler University Linz specializing in Human-Computer-Interaction and Computer Vision. Currently, he conducts research in the area of Human Factors and Driving Ergonomics, focusing on Trust in Automation [22], Intelligent/Attentive User Interfaces [24, 23], and Augmented/ Virtual Reality.

Birsen Donmez is an associate professor of Mechanical \& Industrial Engineering at the University of Toronto, and is the Canada Research Chair in Human Factors and Trans- portation. Her research focuses on driver automation interaction. She was the General Chair for AutomotiveUl'18.

Christian Remy is an assistant professor at the Centre for Digital Creativity at Aarhus University, Denmark. His work and interests focus around a broad range of topics in $\mathrm{HCl}$ and Ubicomp, including sustainable $\mathrm{HCl}$, creativity support tools, and issues of evaluating $\mathrm{HCl}$ research. $\mathrm{He}$ co-organised a SIG on the future of $\mathrm{HCl}$ and sustainability in 2018 [1] and is sustainability co-chair of CHI 2020.

\section{Website}

The workshop website will include the workshop description and goals, call for papers and suggested topics, detailed workshop schedule, ways to get involved during the workshop, and information about the organizers. The accepted position papers will be uploaded on the website before the conference to start a discussion already before the workshop.

https://ubisys.org/chi20-workshop-automotive/

\section{Pre-Workshop Plans}

Before the workshop, to recruit participants, we will distribute a call for papers through $\mathrm{HCl}$ and AutomotiveUIrelated mailing lists (e.g. CHI Announcements), as well as our own lists of potential participants from our previous workshops at $\mathrm{CHI}$ and AutomotiveUl conference (complying with EU GDPR). We will also reach out to the sustainable $\mathrm{HCl}$ community on various channels, such as the relevant mailing lists (e.g., SHCI, ICT4S, LIMITS), as well as the official SIGCHI SHCl community to further disseminate the call. Prior to the workshop, the workshop-related materials and the accepted position papers will be uploaded on our website. 


\begin{tabular}{|l|l|}
\hline Time & Phases \\
\hline $09: 00-$ & Welcome and \\
introduction \\
\hline $09: 30-$ & Opening Keynote \\
$10: 00$ & \\
\hline $10: 00-$ & Poster Session \\
$10: 30$ & \\
\hline $10: 30-$ & Coffee break \\
$10: 50$ & \\
\hline $10: 50-$ & Brainstorming \\
$11: 50$ & (like what Alex \\
& did in 2016 ?!?) \\
\hline $11: 50-$ & Lunch \\
$13: 00$ & \\
\hline $13: 00-$ & World-Cafe-style \\
$14: 00$ & group discus- \\
& sions \\
\hline $14: 20-$ & Presentation of \\
$14: 50$ & results from each \\
& table \\
\hline $14: 50-$ & Coffee break \\
\hline $15: 10$ & \\
\hline $15: 10-$ & Design fiction \\
$16: 10$ & prototyping ses- \\
& sion \\
\hline $16: 10-$ & Presentations \\
of the concepts/ \\
prototypes \\
\hline $16: 40-$ & Exploration of \\
$17: 00$ & future work (e.g. \\
& joint publication) \\
\hline later & and wrap-up \\
\hline & dinner(optional) \\
\hline 10
\end{tabular}

Table 1: Workshop schedule

\section{Workshop Structure}

This is a one-day workshop with presentation, discussion hands-on sessions. We expect approximately 20 participants excluding the organizers. Table 1 shows an overview of the workshop schedule.

We will start the workshop with the self introduction of organizers and participants, as well as a short overview of workshop objectives and agenda. Following this, we will have an opening keynote held by an invited speaker who has been researching in Automotive UI and eco-driving, or Sustainable $\mathrm{HCl}$. To have a more interactive environment, we will not have a classical paper presentation session, instead accepted position papers will be presented as posters during the workshop. This will provide the authors with more time to discuss their work with both organizers and other participants. To support sustainability, we encourage our participants to use an already existing poster (or artefact) that is representing their position papers.

We will close the first half of the workshop with a brainstorming session on interaction concepts and technologies that lead to actions and behaviors that address climate change. The brainstorm session will involve random words methods ${ }^{1}$, which will foster out-of-the-box thinking and sparkle thought-provoking ideas and trans-disciplinary discussions.

We start the second half of the workshop with a world-cafe style discussion session. Having collected the ideas in the brainstorming session, participants will be discussing challenges in designing automotive user interfaces that address climate change and sustainable driving in three discussion tables. Each table will have a host from the workshop organizers who stimulates questions and takes notes for wrap- ping up the discussion topics at the table. We will ask participants to change their table every 20 minutes to make sure they will attend all discussion themes. The results of these discussion tables will be presented in a 10-minute presentation in the following session.

As this is the very first workshop looking at (automated) vehicles and climate change, we considered a design fiction prototyping session to create new interaction concepts by bridging the knowledge from both sustainability and $\mathrm{HCl}$ disciplines. Participants will be grouped into four teams. We will invite them to explore and visualize novel concepts for future interaction based on the results of the world-cafe discussions. We will encourage them to ideate possible future scenarios and will provide them with sustainable (i.e., no plastic waste, degradable) prototyping material for implementing their concepts. Participants of each group will be asked to enact their concept/prototype to present it to the other groups.

\section{Post-Workshop Plans}

After the workshop, we will publish the workshop results on the website and keep it up-to-date to provide an interactive platform for research on topics related to workshop theme. Following the conference, we are planning to prepare a special issue on the workshop reports in a selected journal (e.g. Interactions). We also plan to organize a meet-up during the $\mathrm{CHI}$ conference with other conference attendees who are interested in this topic and future collaborations.

Before and during the workshop we will keep in touch with the sustainability chairs of $\mathrm{CHI} 20$ and sustainable $\mathrm{HCl}$ community, to reflect the outcomes of the workshop in their community meetups and SIGs during and after the conference. Moreover, to keep this research topic going in the community, we will discuss opportunities such as future 
workshops at related conferences to extend the discussions of this workshop (e.g., MobileHCl, AutomotiveUI).

\section{Call for Participation}

"Should I Stay or Should I Go? Automated Vehicles in the Age of Climate Change" - One-day Workshop at CHI2020 in Honolulu, Hawai'i, USA

This workshop aims to gather designers, researchers, and practitioners from the sustainable $\mathrm{HCl}$, persuasive design, AutomotiveUI, and mobility communities to collaborate in finding ways to make future mobility more sustainable. To participate, submit a max. four-page long position paper in the $\mathrm{CHI}$ EA format via the workshop website. Position papers should cover one of the following or related topics:

- Sustainable interaction with (automated) vehicles

- Best practices from other domains

- The effect of automation on sustainability

- Eco driving

- Theory and/or research methods

- Legal issues and/or legislation

- Effect of transportation on climate change

- Cities, mobility, and climate change

- Case studies

Position papers will be reviewed by the workshop organizers and evaluated based on their novelty, quality, and relevance to the workshop themes. One author of the accepted papers is required to attend the workshop and register for both the workshop and for at least one day of the main conference.

Important dates:

Position paper deadline: February 11, 2020

Acceptance notification: February 28, 2020
Workshop at CHI2020: April 25 or 26, 2020

More Information: https://ubisys.org/chi20-workshop-automotive/

\section{Acknowledgement}

This work is supported under the $\mathrm{FH}$-Impuls program of the German Federal Ministry of Education and Research (BMBF) under Grant Number 13FH7I01IA (SAFIR).

\section{REFERENCES}

[1] Oliver Bates, Vanessa Thomas, Christian Remy, Lisa P. Nathan, Samuel Mann, and Adrian Friday. 2018. The Future of $\mathrm{HCl}$ and Sustainability: Championing Environmental and Social Justice.. In Extended Abstracts of the $2018 \mathrm{CHI}$ Conference on Human Factors in Computing Systems (CHI EA '18). ACM, New York, NY, USA, Article SIG01, 4 pages.

DOI : http: //dx.doi.org/10.1145/3170427.3185365

[2] Alex de Ruiter and Miguel Bruns Alonso. 2019. Designing Haptic Effects on an Accelerator Pedal to Support a Positive Eco-Driving Experience. In

Proceedings of the 11th International Conference on Automotive User Interfaces and Interactive Vehicular Applications (AutomotiveUl '19). ACM, New York, NY, USA, 319-328. DOI :

http://dx.doi.org/10.1145/3342197.3344532

[3] Gerald T Gardner and Paul C Stern. 2008. The short list: The most effective actions US households can take to curb climate change. Environment: science and policy for sustainable development 50, 5 (2008), 12-25.

[4] Christian P. Janssen, Shamsi T. Iqbal, Andrew L. Kun and Stella F. Donker. 2019. Interrupted by my car? Implications of interruption and interleaving research for automated vehicles. International Journal of Human-Computer Studies 130 (2019), 221 - 233. 
DOI : http://dx.doi.org/https :

//doi.org/10.1016/j.ijhcs.2019.07.004

[5] Andrew L. Kun. 2018. Human-Machine Interaction for Vehicles: Review and Outlook. Foundations and Trends ${ }^{\circledR}$ in Human-Computer Interaction 11, 4 (2018), 201-293. DOI

http://dx.doi.org/10.1561/1100000069

[6] Tim Kurz, Benjamin Gardner, Bas Verplanken, and Charles Abraham. 2015. Habitual behaviors or patterns of practice? Explaining and changing repetitive climate-relevant actions. Wiley Interdisciplinary Reviews: Climate Change 6, 1 (2015), 113-128.

[7] Thorsten Luettel, Michael Himmelsbach, and Hans-Joachim Wuensche. 2012. Autonomous Ground Vehicles-Concepts and a Path to the Future. Proc. IEEE 100, Centennial-Issue (2012), 1831-1839.

[8] Alexander Meschtscherjakov, Manfred Tscheligi, Bastian Pfleging, Shadan Sadeghian Borojeni, Wendy Ju, Philippe Palanque, Andreas Riener, Bilge Mutlu, and Andrew L Kun. 2018. Interacting with Autonomous Vehicles: Learning from other Domains. In Extended Abstracts of the $2018 \mathrm{CHI}$ Conference on Human Factors in Computing Systems. ACM, W30.

[9] Alexander Meschtscherjakov, Manfred Tscheligi, Dalila Szostak, Sven Krome, Bastian Pfleging, Rabindra Ratan, Ioannis Politis, Sonia Baltodano, Dave Miller, and Wendy Ju. 2016. $\mathrm{HCl}$ and Autonomous Vehicles: Contextual Experience Informs Design. In Proceedings of the $2016 \mathrm{CHI}$ Conference Extended Abstracts on Human Factors in Computing Systems (CHI EA '16). ACM, New York, NY, USA, 3542-3549. DOI : http://dx.doi.org/10.1145/2851581.2856489
[10] Alexander Meschtscherjakov, Manfred Tscheligi, Dalila Szostak, Rabindra Ratan, Roderick McCall, Ioannis Politis, and Sven Krome. 2015. Experiencing Autonomous Vehicles: Crossing the Boundaries Between a Drive and a Ride. In Proceedings of the 33rd Annual ACM Conference Extended Abstracts on Human Factors in Computing Systems (CHI EA '15). ACM, New York, NY, USA, 2413-2416. DOI : http://dx.doi.org/10.1145/2702613.2702661

[11] Alexander Meschtscherjakov, David Wilfinger, Thomas Scherndl, and Manfred Tscheligi. 2009. Acceptance of future persuasive in-car interfaces towards a more economic driving behaviour. In Proceedings of the 1st International Conference on Automotive User Interfaces and Interactive Vehicular Applications (2009-01-01) (AutomotiveUl '09). ACM, New York, NY, USA, 81-88.

[12] Gregory James Offer. 2015. Automated vehicles and electrification of transport. Energy \& Environmental Science 8, 1 (2015), 26-30.

[13] Bastian Pfleging. 2017. Automotive User Interfaces for the Support of Non-Driving-Related Activities. Ph.D. Dissertation. University of Stuttgart, Stuttgart, Germany. DOI :

http://dx.doi.org/10.18419/opus-9090

[14] Benjamin Pichler and Andreas Riener. 2015. Evaluation of Historical Electric Vehicle (EV) Driving Data to Suggest Improvements in Driving Efficiency. In Adjunct Proceedings of the 7th International Conference on Automotive User Interfaces and Interactive Vehicular Applications (AutomotiveUI '15). ACM, New York, NY, USA, 130-135. DOI : http://dx.doi.org/10.1145/2809730.2809756 
[15] Andreas Riener and Johann Reder. 2014. Collective Data Sharing to Improve on Driving Efficiency and Safety. In Adjunct Proceedings of the 6th International Conference on Automotive User Interfaces and Interactive Vehicular Applications (AutomotiveUI '14). ACM, New York, NY, USA, 1-6. DOI : http://dx.doi.org/10.1145/2667239.2667266

[16] A. Riener, K. Zia, A. Ferscha, C. Ruiz Beltran, and J. J. Minguez Rubio. 2013. Traffic flow harmonization in expressway merging. Personal and Ubiquitous Computing 17, 3 (01 Mar 2013), 519-532. DOI : http://dx.doi.org/10.1007/s00779-012-0505-6

[17] Dirk Rothenbücher, Jamy Li, David Sirkin, Brian Mok, and Wendy Ju. 2016. Ghost driver: A field study investigating the interaction between pedestrians and driverless vehicles. In Robot and Human Interactive Communication (RO-MAN), 2016 25th IEEE International Symposium on. IEEE, 795-802.

[18] Shadan Sadeghian Borojeni, Susanne C.J. Boll, Wilko Heuten, Heinrich H. Bülthoff, and Lewis Chuang. 2018. Feel the Movement: Real Motion Influences Responses to Take-over Requests in Highly Automated Vehicles. In Proceedings of the $2018 \mathrm{CHI}$ Conference on Human Factors in Computing Systems (CHI '18). ACM, New York, NY, USA, Article 246, 13 pages. DOI :

http://dx.doi.org/10.1145/3173574.3173820

[19] Shadan Sadeghian Borojeni, Alexander Meschtscherjakov, Bastian Pfleging, Wendy Ju, Frank Flemisch, Christian P. Janssen, Andrew L. Kun, and Andreas Riener. 2019. Looking into the Future: Weaving the Threads of Vehicle Automation. In
Extended Abstracts of the $2019 \mathrm{CHI}$ Conference on Human Factors in Computing Systems (CHI EA '19). ACM, New York, NY, USA, Article W08, 8 pages. DOI : http://dx.doi.org/10.1145/3290607.3299031

[20] Bruce Sterling. 2009. COVER STORY: Design Fiction. Interactions 16, 3 (May 2009), 20-24. DOI : http://dx.doi.org/10.1145/1516016.1516021

[21] SAE Taxonomy. 2018. SAE J3016 Definitions for terms related to on-road motor vehicle automated driving systems. Technical Report. Technical report, Technical report, SAE International.

[22] Philipp Wintersberger, Anna-Katharina Frison, Andreas Riener, and Tamara von Sawitzky. 2019. Fostering User Acceptance and Trust in Fully Automated Vehicles: Evaluating the Potential of Augmented Reality. PRESENCE: Virtual and Augmented Reality 27, 1 (2019), 46-62.

[23] Philipp Wintersberger, Andreas Riener, Clemens Schartmüller, Anna-Katharina Frison, and Klemens Weigl. 2018. Let Me Finish before I Take Over: Towards Attention Aware Device Integration in Highly Automated Vehicles. In Proceedings of the 10th International Conference on Automotive User Interfaces and Interactive Vehicular Applications. ACM, 53-65.

[24] Philipp Wintersberger, Clemens Schartmüller, and Andreas Riener. 2019. Attentive User Interfaces to Improve Multitasking and Take-Over Performance in Automated Driving: The Auto-Net of Things. International Journal of Mobile Human Computer Interaction (IJMHCl) 11, 3 (2019), 40-58. 